\title{
A volatilidade eleitoral nos municípios brasileiros para o cargo de vereador (2000-2016)
}

Monize Arquer ${ }^{1}$ (i)

O objetivo deste artigo é demonstrar que o contexto local (sociodemográfico e institucional) ajuda a explicar a alternância na decisão do eleitor entre os diversos partidos políticos. Para isso, analisa o índice de volatilidade eleitoral partidária para o cargo de vereador em cinco eleições consecutivas - 2000, 2004, 2008, 2012 e 2016 - tendo como base uma amostra representativa de todos os municípios brasileiros e tratando esse índice como variável dependente. Assim, o artigo contribui para a literatura sobre sistema partidário e sobre comportamento eleitoral. Os resultados encontrados indicam um efeito mais expressivo das variáveis contextuais entre os municípios de pequeno porte e no início do período analisado. Palavras-chave: volatilidade eleitoral; eleições municipais; comportamento eleitoral; sistema partidário; vereador

\section{Introdução}

Um elemento bastante analisado dentro de um sistema partidário é o índice de volatilidade eleitoral, que mede o quanto os eleitores mudam de partido entre duas eleições consecutivas (Pedersen, 1979; Mainwaring e Scully, 1995). Esse índice permite identificar características importantes do funcionamento do sistema partidário, como o grau de adesão partidária dos eleitores e a estabilidade da competição eleitoral e do sistema partidário como um todo (Mainwaring e Scully, 1995). Normalmente, ele aparece em trabalhos como variável independente, como possível explicação para eventos mais amplos, mas ainda pouco se estudou sobre aspectos que interferem na sua variação (Peres, Ricci e Rennó, 2011; Peres, 2013). O presente artigo visa preencher essa lacuna explorando elementos que possam interferir na mudança de decisão do eleitor e, com isso, influenciar o índice de volatilidade eleitoral partidária nos municípios brasileiros.

O objetivo é verificar em que medida características contextuais sociodemográficas e institucionais - dos municípios são capazes de explicar o índice de volatilidade eleitoral. Para isso, analisa-se a volatilidade eleitoral partidária para o cargo de vereador nos municípios brasileiros entre 2000 e 2016, compreendendo cinco eleições e quatro pares eleitorais para o cálculo do índice. Esse olhar para o nível subnacional

\footnotetext{
1 Universidade Estadual de Campinas, Campinas (SP), Brasil. E-mail: <monize.arquer@hotmail.com>.
} 
permite compreender como se dá a dinâmica eleitoral no interior dos municípios, identificar especificidades da disputa política local e verificar em que medida ela acompanha os níveis estaduais e nacional, aspectos que ainda foram pouco explorados no Brasil.

A volatilidade eleitoral consiste em uma das medidas propostas por Mainwaring e Scully (1995) para medir o grau de institucionalização dos sistemas partidários. Desde então, seu uso mais frequente tem sido nessa área. Normalmente, trata-se de pesquisas comparadas e sobre países da América Latina que, devido ao seu recente processo de democratização, passam por estruturação e consolidação do novo regime político. Nessa nova conjuntura, a volatilidade seria um indicador adequado para analisar o desenvolvimento de seu sistema partidário, pois indica a adesão dos eleitores aos partidos e a estabilidade da competição eleitoral (Mainwaring e Scully, 1995; Mair, 1997; Mainwaring e Torcal, 2005; Mainwaring e Zoco, 2007).

No Brasil, alguns trabalhos seguiram esse caminho para tratar da estabilidade e do desenvolvimento do sistema partidário (Mainwaring, 2001; Braga, Ribeiro e Amaral, 2012). Outros se preocuparam mais detidamente com a volatilidade eleitoral, buscando identificar padrões entre cargos e níveis de disputa (Braga, 2006; Bohn e Paiva, 2009). Em especial, alguns estudos se dedicaram a explicar a variação da volatilidade eleitoral entre os estados brasileiros e propuseram uma interpretação alternativa, preocupando-se menos com seu valor e mais com a composição desse índice e a dinâmica da competição eleitoral (Peres, Ricci e Rennó, 2011; Peres, 2013).

Esses trabalhos trouxeram contribuições importantes para a compreensão sobre o sistema partidário brasileiro e os índices de volatilidade eleitoral. Todavia, o nível municipal ainda não foi amplamente estudado, e falta olhar a relação entre contexto e volatilidade eleitoral nas disputas municipais. A variedade numérica e a diversidade social e política dos municípios brasileiros permitem ampliar o número de casos e inserir novos elementos na análise. Olhar como essas características se relacionam com o comportamento político e o sistema partidário subnacional é de extrema importância para compreender como se estrutura o sistema partidário local e as suas relações com o comportamento eleitoral e com as estratégias partidárias nos demais níveis de disputa.

Este artigo tem como principal contribuição preencher a lacuna na literatura no que tange a explicar os elementos comportamentais e contextuais que afetam a volatilidade eleitoral partidária no nível municipal. A importância desta análise reside também no fato de oferecer um olhar alternativo e mais aprofundado para um índice amplamente utilizado. Aqui ele deixa de ser tratado como um valor classificatório, para ser compreendido como resultado de outras características que são igualmente importantes para avaliar o funcionamento de sistemas partidários: a relação entre eleições e contextos.

O artigo está dividido em quatro seções, além desta Introdução. A primeira, "Contexto e volatilidade eleitoral no Brasil", traz um breve referencial teórico com os pressupostos que orientam a pesquisa, tratando da relação entre sistema partidário e contexto, com destaque ao índice de volatilidade eleitoral. A seção seguinte, "Metodologia 
e desenho de pesquisa", traz o desenho de pesquisa de forma detalhada, apresentando a metodologia e as variáveis que serão consideradas, com suas respectivas justificativas e hipóteses. A estratégia utilizada foi criar uma amostra estratificada por região e representativa de todos os municípios brasileiros, e foram realizadas tanto análises descritivas como regressões lineares, visando à maior precisão nos resultados. A volatilidade eleitoral atua como variável dependente, e as variáveis independentes agregam características tanto sociais quanto institucionais: IDHM, tamanho do eleitorado, porcentagem de população que vive na zona rural, número efetivo de partidos e tamanho do distrito eleitoral. Em "Resultados e análise", avaliam-se a variação do índice no nível local e o impacto do contexto. De um modo geral, foi possível identificar que o contexto tem alguma influência na decisão do eleitor e, assim, ajuda a explicar a volatilidade eleitoral. Os principais impactos se referem ao grau de desenvolvimento local, à porcentagem de população rural e ao número efetivo de partidos, sendo essas relações mais presentes em municípios pequenos. Por fim, nas "Considerações finais" são apresentadas as conclusões baseadas nesses achados e as possíveis agendas de pesquisa futura.

\section{Contexto e volatilidade eleitoral no Brasil}

Este artigo parte do pressuposto de que o contexto importa para explicar a decisão do eleitor e que por meio de características locais é possível compreender os fatores que interferem na alternância partidária entre duas eleições consecutivas. Essa análise está ancorada na abordagem sociológica, ou teoria histórico-contextual, que defende que a preocupação fundamental do pesquisador deve ser as condições sociais nas quais o indivíduo está inserido. O eleitor seria influenciado pelo contexto social e político em que vive, pela forma como vive nesse local e pelos coletivos dos quais faz parte, que integram socialmente os indivíduos e ajudam a compor o eixo que direcionará suas atitudes e comportamentos. É nesse contexto que as instituições, as práticas cotidianas e as ideologias se formam, se consolidam e orientam o caminho a ser seguido pelo eleitor (Figueiredo, 2008).

Essa relação entre contexto local e sistema partidário foi apresentada por Lipset e Rokkan (1967). Nesse estudo, ficou demonstrado que a origem e as estruturas dos sistemas partidários europeus estão associadas às clivagens sociais que permeavam a sociedade: igreja x governo, economia primária x economia secundária, trabalhadores $\mathrm{x}$ proprietários dos meios de produção, e novos temas culturais $x$ cultura dominante. Essas clivagens surgiram após a consolidação do território nacional e estão presentes em toda sua extensão. Cada uma delas se manifesta em alinhamentos partidários específicos de acordo com os objetivos dos diferentes setores, visando a algum retorno vantajoso (Lipset e Rokkan, 1967). 
Com essa análise os autores foram capazes de explicar a gênese dos sistemas políticos e a consolidação das bases partidárias em contextos específicos. Essas características contextuais agregam eleitores ao redor de preferências e demandas específicas, conforme seu posicionamento em cada ponto dessas relações conflitantes que permeiam a sociedade. Sendo assim, partidos devem atuar em conformidade com essas clivagens para que sejam representativos e influenciem a comunidade política, conseguindo votos e sucesso eleitoral. Por exemplo, eles podem direcionar sua campanha e propaganda políticas para grupos mais delineados, respondendo às demandas específicas e garantindo sucesso eleitoral e capacidade de influência na comunidade política. Essas conexões entre o sistema e a sociedade reforçam o vínculo existente entre partidos e eleitores, e indicam uma relação direta entre as características da sociedade e a ação política, o que resulta em dinâmicas partidárias específicas a cada local.

Desde então, essa relação entre contexto e sistemas partidários segue sendo demonstrada em trabalhos posteriores, que utilizam o contexto para explicar o desenvolvimento, as mudanças e as continuidades dos sistemas partidários. Muitos deles apontam a mudança nas clivagens com o passar do tempo, destacando a impossibilidade de identificar os mesmos padrões nos períodos mais recentes, com exceção das clivagens de classe e religiosa, que ainda apresentam alguma relação com o voto (Pedersen, 1983; Dalton, 1996; Bornschier, 2009). Apesar dessa mudança no padrão apresentado por Lipset e Rokkan (1967), ainda é possível identificar relações importantes entre uma posição na estrutura social e um partido político, havendo ainda determinação entre os conflitos de valor e os alinhamentos partidários (Mair, 2001). Na verdade, as mudanças nessas clivagens são uma das possíveis explicações para as mudanças nos sistemas partidários e no comportamento do eleitorado como um todo (Dalton, 1996). Ou, ainda, a continuidade de clivagens específicas pode indicar uma possível institucionalização do sistema, entendida como maior estabilidade e previsibilidade em seu funcionamento (Bornschier, 2009).

Vale destacar que "contexto" não se refere apenas às características demográficas ou socioeconômicas de determinada sociedade, mas também às regras e instituições que permeiam a vida dos atores e influenciam suas ações. Essa influência das instituições se torna mais evidente em relação ao processo eleitoral. Segundo Dalton e Anderson,

voters may react to the more proximate and identifiable options existing in the party system that flows from theses institutional structures. We presume that the political context defined by the electoral system and party system shapes the voters' behavior in three ways: by determining the number of choices, the nature of choices, and the predictability of choices (Dalton e Anderson, 2011, p. 9).

A relação entre contexto e sistema partidário foi demonstrada por meio de trabalhos empíricos que corroboram as suposições teóricas adotadas e dão consistência ao 
presente artigo. Esses trabalhos integram características locais de natureza diversa e demonstram sua capacidade explicativa. Aqui cabe destacar o que diz respeito especificamente à volatilidade eleitoral. Por se tratar de um importante indicador sobre o funcionamento do sistema partidário, essa relação ajuda a demonstrar a influência dessas caraterísticas tanto no comportamento dos partidos quanto no comportamento dos eleitores, resultando em sistemas partidários com dinâmicas específicas.

Pesquisas comparativas, principalmente entre países da América Latina, demonstram tal relação. Países com maior Índice de Desenvolvimento Humano (IDH) e maior produto interno bruto (PIB) per capita tendem a apresentar uma menor volatilidade eleitoral, indicando a relação de riqueza e grau de desenvolvimento com a estabilidade dos sistemas partidários (Mainwaring e Torcal, 2005). No mesmo sentido, maiores valores de número efetivo de partidos (NEP), baixo crescimento econômico e tempo de existência do regime democrático também exerceram influência na alta da volatilidade eleitoral (Mainwaring e Zoco, 2007). Além desses fatores, a alta volatilidade também pode ser explicada com base em perturbações econômicas de curto prazo que esses países sofreram, maiores graus de fragilidade institucional e presença de clivagens relativamente fluídas (Roberts e Wibbels, 1999).

No Brasil também ficou demonstrada essa relação. No início do processo de redemocratização, a mudança de sistema e, consequentemente, de regras eleitorais e partidos afetou diretamente o novo sistema em formação, resultando em uma alta volatilidade para os cargos de deputado federal e presidente de 1979 a 1996 (Mainwaring, 2001). Mas, quando essa análise era feita considerando diferentes regiões, estados e portes de municípios, era possível notar alguma continuidade nas preferências eleitorais, indicando a relação entre as características demográficas desses locais e o funcionamento do sistema partidário (Mainwaring, 2001).

No período mais recente, essa tendência permaneceu. Além da redução dos valores da volatilidade eleitoral, ficou demonstrado que ela varia de acordo com as regiões e tamanho de municípios (Braga, 2006). A volatilidade tendeu a ser maior em municípios pequenos e médios, e menor em municípios grandes, capitais e nas regiões Sul e Sudeste, entre os anos de 1982 e 2002 (Braga, 2006). Uma possível explicação para essas diferenças está no processo de instauração do pluripartidarismo, que levaria a uma alta volatilidade em locais nos quais isso ocorreu de forma mais lenta, como nas regiões Norte, Nordeste e Centro-Oeste, o que fez com que a mudança na correlação de forças partidárias acontecesse mais recentemente (Braga, 2006).

Mas, além dessas características sociais e demográficas, variáveis institucionais também compõem o contexto e apresentam relações importantes com o funcionamento do sistema partidário e, mais especificamente, com a volatilidade eleitoral. Entre 1982 e 2006, houve redução e homogeneização da volatilidade eleitoral nas disputas presidenciais, continuidade e heterogeneidade interestadual nas disputas para os governos estaduais e maior instabilidade nas disputas senatoriais (Bohn e Paiva, 2009). Já as 
disputas proporcionais tiveram índices menores de volatilidade eleitoral, aproximando-se do que é visto no cenário nacional (Bohn e Paiva, 2009). Parte da explicação para esses eventos está na magnitude do distrito e nas regras eleitorais majoritária ou proporcional. Essas características afetam o resultado eleitoral, gerando essa variação no valor de acordo com regras, tamanhos e níveis da disputa (Bohn e Paiva, 2009). Ou seja, "particularidades subnacionais de fato contribuem para o entendimento das taxas de volatilidade eleitoral" (Bohn e Paiva, 2009, p. 204).

A importância de variáveis institucionais e políticas se confirma também quando analisadas em conjunto com variáveis econômicas e sociais. Esse exercício permite melhor interpretação da relação entre contexto e volatilidade eleitoral, pois envolve diversas características presentes no cotidiano da população que podem exercer alguma influência sobre seu comportamento. Especificamente nas disputas para a Câmara dos Deputados, houve declínio da volatilidade eleitoral com significativa variação entre os estados, e um predomínio do impacto de características políticas sobre a volatilidade eleitoral, como o número efetivo de partidos, o tamanho do distrito eleitoral, as migrações partidárias, entre outras (Peres, Ricci e Rennó, 2011). Esse achado reforça o impacto do contexto e incentiva a realização de análises mais desagregadas, pois só assim é possível captar efeitos e variações em locais específicos e interpretar o significado da volatilidade eleitoral e seu impacto sobre o funcionamento do sistema partidário.

Ficou demonstrado que a volatilidade eleitoral é amplamente utilizada nas análises sobre o sistema partidário brasileiro, assim como a diversidade de seus resultados e de possibilidades explicativas. Isso sugere que, para interpretar o significado do valor desse índice, é importante realizar uma análise mais aprofundada, olhar para os contextos nos quais os indivíduos estão inseridos, realizar pesquisas comparativas e temporais que demonstrem os possíveis efeitos que procedimentos distintos podem gerar e considerar as mudanças que esses locais podem sofrer ao longo do tempo (Dalton e Anderson, 2011). É nesse sentido que o presente artigo explora o nível mais desagregado da disputa política, o municipal, e trabalha com características sociais e institucionais das cidades, a fim de traçar a relação existente entre o sistema partidário e o contexto local em ambientes ainda pouco estudados.

\section{Metodologia e desenho de pesquisa}

A volatilidade eleitoral mede o quanto os eleitores mudam de opção partidária entre duas eleições consecutivas. Sua fórmula original foi elaborada por Pedersen (1979), e consiste na diferença entre a porcentagem de votos recebidos pelos partidos políticos em cada par de eleições ${ }^{2}$. Como já mencionado na Introdução do artigo, normalmente ela

\footnotetext{
2 Para a volatilidade eleitoral, foi calculada a diferença na porcentagem de votos em cada um dos partidos entre duas eleições consecutivas. Essas diferenças foram somadas (desconsiderando o sinal) em cada
} 
aparece como um dos indicadores necessários para medir a institucionalização de um sistema partidário, juntamente com o enraizamento dos partidos na sociedade, a legitimidade das leis e regras que direcionam a disputa e a consolidação da organização partidária; e é interpretada como uma evidência do grau de estabilidade da competição eleitoral (Mainwaring e Scully, 1995). Todavia, este artigo trata a volatilidade eleitoral como variável dependente, sendo utilizada como uma ferramenta para identificar possíveis explicações para o comportamento eleitoral.

Essa análise tem o município como unidade. Para isso, foram estabelecidos três grupos de cidades de acordo com seu porte, com base no número de eleitores. Para o primeiro e o segundo grupos foi criada uma amostra estratificada proporcional por região ${ }^{3}$. O primeiro contempla os municípios pequenos, de até 20 mil eleitores, e é composto por 532 municípios; o segundo representa os municípios médios, com mais de 20 mil a 200 mil eleitores e conta com 393 municípios. Já o terceiro abarca todos os municípios grandes, com mais de 200 mil eleitores, sendo composto por 82 municípios ${ }^{4}$. A descrição completa dos grupos de municípios em cada região pode ser vista na Tabela 1:

município e o resultado dessa soma foi dividido por dois. Para os casos de fusões e criação de novos partidos que aconteceram ao longo do período estudado, foi realizado o seguinte procedimento: 1) para o primeiro caso, foi considerada a soma dos votos que os partidos que se uniram receberam na eleição anterior à fusão; e 2) para o segundo caso, foi considerado que o número de votos que o novo partido recebeu na eleição anterior ao seu surgimento foi igual a zero.

${ }^{3}$ A fórmula para calcular a amostra é:

$$
n=\frac{N \cdot Z^{2} \cdot p \cdot(1-p)}{Z^{2} \cdot p \cdot(1-p)+e^{2} \cdot(N-1)}
$$

Sendo que: $\mathrm{n}$ - tamanho da amostra calculada

$\mathrm{N}$ - tamanho da população

Z - variável normal padronizada associada ao nível de confiança (95\%)

$\mathrm{p}$ - verdadeira probabilidade do evento

e - erro amostral (4 pontos percentuais)

${ }^{4}$ A pesquisa que deu origem a este artigo tinha como base o ano de 2012 para a construção da amostra. Os resultados para 2016 foram incluídos a fim de atualizar e testar os efeitos das análises no atual momento de crise do país. Nesse último ano alguns municípios extrapolaram os 200 mil eleitores, mas como essa alteração foi pequena, decidiu-se manter os dados referentes a 2012 na análise. Assim, foram considerados 82 dos 84 municípios com mais de 200 mil eleitores em 2012, excluindo apenas Brasília (DF), por não ter eleições para o cargo de vereador, e Campos dos Goytacazes (RJ), que teve as eleições de 2004 anuladas após uma intervenção judicial, o que poderia distorcer os dados. 
Tabela 1

Número de municípios por região

\begin{tabular}{|l|c|c|c|c|}
\hline & $\begin{array}{c}\text { Pequenos } \\
\text { (0 a 20 mil) }\end{array}$ & $\begin{array}{c}\text { Médios } \\
\text { (mais de 20 a } \\
\mathbf{2 0 0} \mathbf{~ m i l )}\end{array}$ & $\begin{array}{c}\text { Grandes } \\
\text { (mais de 200 mil) }\end{array}$ & Total \\
\hline Norte & 42 & 37 & 6 & 85 \\
\hline Nordeste & 170 & 133 & 14 & 198 \\
\hline Sul & 121 & 65 & 45 & 329 \\
\hline Sudeste & 151 & 133 & 5 & 78 \\
\hline Centro-Oeste & 48 & 25 & 82 & 1.007 \\
\hline Total & 532 & 393 & 12 & \\
\hline
\end{tabular}

Fonte: Elaborada pela autora com base em dados do TSE. Disponível em: <http://www.tse.jus.br>. Acesso em: 17 set. 2017.

Para medir o impacto do contexto nesses locais, foram utilizadas variáveis sociodemográficas e institucionais. O grupo das variáveis estruturais ou sociodemográficas inclui o Índice de Desenvolvimento Humano Municipal (IDHM), o tamanho do eleitorado (número de eleitores) e a porcentagem da população que vive na zona rural. Já o grupo que contempla as variáveis institucionais inclui o número efetivo de partidos (NEP) e a magnitude do distrito (número de vagas) ${ }^{5}$.

O principal método utilizado foi a regressão linear múltipla, que permite analisar o efeito de cada variável, ou grupo de variáveis, dentro de modelos específicos, considerando a presença das outras variáveis que o compõem. Para este artigo foram realizados três modelos, sendo a volatilidade eleitoral partidária variável dependente. O primeiro modelo traz apenas o IDHM como uma forma de avaliar a qualidade de vida no município, o grau de desenvolvimento local e o impacto da maior escolaridade e da economia, que facilitaria a existência de comportamentos mais estáveis no tempo. O segundo modelo acrescenta as variáveis sociodemográficas, ou seja, o tamanho do eleitorado e a porcentagem de população rural. Foi criado, portanto, um bloco de variáveis que tratam não só da qualidade de vida, mas também das condições de vida e do processo de socialização, uma vez que municípios menores e mais rurais tendem a ter uma dinâmica distinta dos grandes centros urbanos $^{6}$. Por fim, o terceiro modelo inclui as variáveis institucionais: o número efetivo de

\footnotetext{
5 Os dados referentes às variáveis estruturais foram obtidos através dos sites do Instituto Brasileiro de Geografia e Estatística - IBGE (<www.ibge.gov.br>), do Instituto de Pesquisa Econômica Aplicada - Ipea (<www.ipea.gov.br>) e do Atlas de Desenvolvimento Humano no Brasil (<www.atlasbrasil.org.br/2013>). Já as variáveis institucionais, assim como os dados eleitorais, foram obtidas através do site do Tribunal Superior Eleitoral - TSE (<www.tse.jus.br $>$ ).

${ }^{6}$ Os testes foram realizados utilizando o IDHM de cada município multiplicado por mil e o log do número de eleitores de cada município. Isso foi feito pois seus valores originais destoam em amplitude, e para realizar
} 
partidos (NEP) e o número de vagas para o cargo analisado (vereador). Com elas é possível saber como as regras e a organização da disputa política influenciam o eleitorado. Acrescentar essas variáveis apenas no modelo final permite captar o impacto institucional separadamente?.

É importante ressaltar que, à medida que as variáveis são acrescentadas a cada modelo, este amplia seu poder explicativo. Ou seja, o $r^{2}$ apresentou tendência crescente a cada modelo realizado, indicando que há maior eficácia da análise e que as variáveis são significativas para explicar a volatilidade eleitoral quando tratadas em conjunto. Os testes foram feitos separadamente para cada grupo de municípios (pequenos, médios e grandes), e os resultados serão apresentados: 1 ) de forma comparativa entre os grupos, para que seja possível verificar como o porte municipal exerce impacto sobre o comportamento do eleitorado; e 2) entre os três pares de volatilidade eleitoral partidária, para verificar a existência de padrões estáveis a cada período. Desse modo é possível explorar as diferenças que existem em relação a essa característica fundamental que é o porte do município, e identificar como o impacto das variáveis se comporta no decorrer do tempo. Outra vantagem dessa pesquisa consiste no fato de as cidades estarem no mesmo país, o que permite uma análise comparativa isolando unicamente as características contextuais, dado que todos os municípios estão sujeitos às mesmas regras eleitorais.

A escolha das variáveis independentes se relaciona diretamente com as hipóteses deste artigo, definidas com base nas teorias apresentadas anteriormente. Aqui serão apresentadas cada uma dessas hipóteses a fim de justificar as escolhas e amparar as análises realizadas na seção seguinte, "Resultados e análise".

Já ficou demonstrado que em países mais desenvolvidos e ricos a volatilidade tende a ser menor, principalmente pela maior integração existente entre partidos e eleitores, pela menor variação na oferta partidária e pelo menor prejuízo que uma performance econômica ruim poderia gerar aos partidos governistas (Mainwaring e Torcal, 2005; Mainwaring e Zoco, 2007). Além disso, pressupõe-se que locais com menor nível educacional favoreçam a existência de personalismo e clientelismo, reduzindo o vínculo partidário e, assim, tornando mais propício o aumento da volatilidade (Peres, Ricci e Rennó, 2011). Cabe explorar se isso também se aplica aos municípios brasileiros, o que será feito por meio do IDHM, índice composto por três medidas que integram essas características: educação, calculada pela taxa de analfabetismo e matrícula; longevidade, que se baseia na esperança de vida ao nascer; e renda, calculada com o valor do Produto Interno Bruto (PIB) per capita. Seu valor varia entre 0, que significa nenhum desenvolvimento humano, e 1 , que seria o desenvolvimento humano completo. As medidas que o compõem dizem respeito às condições básicas e fundamentais presentes no município, e consistem em uma

\footnotetext{
a regressão linear múltipla as variáveis precisam estar na mesma escala. Nesse exercício, as variáveis têm a mesma unidade de medida, o que torna os coeficientes comparáveis.

7 Foram realizados testes de multicolinearidade entre as variáveis em cada um dos modelos e todos deram negativo.
} 
forma de mensurar a qualidade de vida e o grau de desenvolvimento social e econômico de seus habitantes e em uma possível forma de ponderar sobre a relação entre os cidadãos e a política local.

Assim, quanto mais próximo de 1 for o IDHM de um município, melhor é a qualidade de vida dos moradores, mais desenvolvidos social e economicamente são esses locais, menor é a taxa de analfabetismo e, espera-se, mais estável é o posicionamento político dos eleitores, favorecendo a existência de relações mais duradouras entre cidadãos e partidos. Logo, em municípios com maior IDHM, a relação dos eleitores com a política e suas preferências partidárias seriam mais estáveis, gerando uma menor alteração no voto. Portanto, municípios com maior IDHM apresentariam volatilidade eleitoral menor (Mainwaring e Torcal, 2005; Mainwaring e Zoco, 2007).

Outra característica é o tamanho do eleitorado de cada município. Ele está diretamente relacionado com o tamanho da população e ajuda a compreender a composição do eleitorado local. Municípios pequenos tenderiam a apresentar um eleitorado mais homogêneo em relação às suas opiniões e seus comportamentos, enquanto uma grande população propicia a formação de grupos menores e um eleitorado mais heterogêneo em sua totalidade. Pesquisadores da abordagem sociológica seguem essa linha de pesquisa, analisando os coletivos dos quais o eleitor faz parte para interpretar seu comportamento. Locais menores teriam menor segmentação e variação em coletivos internos, o que propicia maior concordância em relação a demandas e preferências e na direção das ações políticas. Logo, espera-se que municípios menores tenham uma volatilidade eleitoral também menor, uma vez que há menor heterogeneidade de propostas e menos interesses concorrentes, promovendo uma menor flutuação das preferências e escolhas (Lipset e Rokkan, 1967; Braga, 2006; Figueiredo, 2008).

A terceira variável mede a porcentagem da população que vive na zona rural da cidade e segue o mesmo raciocínio. Em alguma medida, essa variável está associada ao porte, uma vez que municípios maiores tendem a ser mais urbanizados. Mas ela também está associada principalmente às condições de vida local e atividades cotidianas, permitindo uma análise que não só quantifica um município com base em seu tamanho, mas que principalmente o qualifica com base em características estruturais. Um município majoritariamente rural oferece a seus habitantes formas de vida, locais de trabalho e meios de subsistência semelhantes. Provavelmente, o setor da economia predominante nesses locais é o primário ${ }^{8}$, com atividades relativas a agricultura, pecuária, entre outras. Essa dinâmica produtiva e de vivência cotidiana geraria preferências e demandas similares, estimulando avaliações e comportamentos concordantes e estáveis, como o que ocorria

\footnotetext{
${ }^{8}$ A divisão da população economicamente ativa é a seguinte: setor primário (agricultura, pesca, pecuária, extração vegetal, caça e mineração); setor secundário (produção industrial); e setor terciário (prestação de serviços).
} 
com as clivagens descritas por Lipset e Rokkan (1967)9 . Espera-se, portanto, que em municípios com maior porcentagem da população vivendo na área rural a volatilidade seja menor devido à maior homogeneidade e estabilidade na formação de opiniões e preferências da população local.

Em relação às variáveis institucionais, a intenção é compreender como as regras e a organização da disputa política influenciam o comportamento do eleitorado. A primeira delas é o número efetivo de partidos $(\mathrm{NEP})^{10}$. É um valor mais específico do que o número de agremiações que lançaram ou elegeram candidatos, pois pondera quantos foram verdadeiramente competitivos. O NEP mostra quão fragmentado está o sistema partidário, o que pode dificultar a formação de lealdades políticas devido à ampla gama de opções disponíveis. Nesses casos, a chance de haver partidos com propostas semelhantes aumenta, o que dificulta a formação de lealdades partidárias e a decisão do eleitor, facilitando que ele transite entre as legendas. Partindo desse pressuposto, em municípios onde há um alto NEP, a volatilidade eleitoral seria maior (Roberts e Wibbels, 1999; Mainwaring e Zoco, 2007; Peres, Ricci e Rennó, 2011).

Por fim, a segunda variável institucional é a magnitude do distrito, mensurada por meio do número de vagas para o cargo de vereador em cada município. Segundo Taagepera e Shugart (1989), esse é um aspecto importante em análises sobre o sistema partidário, e tem relação direta com a distribuição de votos entre os partidos. 0 pressuposto para o uso dessa variável é semelhante ao da anterior mas se relaciona menos com a fragmentação do sistema e mais com as estratégias de competição dos partidos. Um maior número de vagas disponíveis tende a gerar mais incentivos para os partidos lançarem candidatos devido à maior chance que têm de conquistar uma dessas vagas, aumentando o número de competidores e, consequentemente, as opções disponíveis aos eleitores. Um maior número de partidos dificultaria a continuidade das escolhas e, por isso, em municípios com maior número de vagas, a volatilidade eleitoral seria maior (Bohn e Paiva, 2009; Peres, Ricci e Rennó, 2011).

\section{Resultados e análise}

Esta seção apresenta análises descritivas e se propõe a explicar os motivos de haver locais com eleitores mais voláteis, ou seja, que transitam mais entre as opções partidárias. Antes disso é necessário entender como esse índice se comporta em todo o

\footnotetext{
9 Segundo Peres, Ricci e Rennó (2011), não seria possível considerar que a população que vive em determinada área seja homogênea e, para substituir essa variável em sua pesquisa, os autores utilizam o setor de ocupação da população economicamente ativa (PEA). Todavia, o presente artigo visa analisar o efeito que um modo de vida em específico tem sobre o processo de decisão do eleitor e, assim, a porcentagem da população rural seria suficiente.

10 Para calcular o número efetivo de partidos é preciso somar a fração de votos que cada partido recebeu em uma eleição para o cargo analisado. Essas frações são elevadas ao quadrado e, em seguida, esse valor é somado para cada município. Por fim, divide-se o número 1 por essa soma, ou seja, 1/soma dos quadrados das frações de voto (Laakso e Taagepera, 1979).
} 
país. O cálculo foi realizado considerando a porcentagem de votos de todos os partidos separadamente para cada par de eleições. Os dados são apresentados para cada porte de município e par eleitoral. Na Tabela 2 está a média da volatilidade eleitoral partidária para as quatro ondas analisadas.

É possível notar que esse índice se apresenta diferente dependendo do porte do município; os municípios grandes se destacam com um valor comparativamente menor, o qual praticamente se mantém contínuo ao longo dos anos. Já os outros dois grupos apresentam médias semelhantes. Entre 2000 e 2012 notam-se algumas mudanças no índice mas elas não são suficientemente expressivas. Já entre 2012 e 2016 nota-se um aumento semelhante nos três grupos. Esse aumento pode ser explicado tendo em vista o momento político pelo qual o país passou após as eleições de 2014 .

Desde 2014, houve muito conflito entre as elites políticas eleitas naquele ano, a isso se somam a insatisfação do resultado da disputa presidencial daquele ano, o aumento das investigações e as divulgações de grandes escândalos de corrupção, culminando no impeachment da presidenta eleita Dilma Rousseff (Partido dos Trabalhadores - PT). Essa conjuntura prejudicou, principalmente, o PT, e o resultado disso foi percebido nas eleições de 2016, com a redução no número de candidatos lançados pelo partido e o aumento da volatilidade eleitoral partidária nos municípios brasileiros. Esse aumento pode indicar que partidos que disputaram a eleição anterior não estavam presentes no pleito seguinte, mas também pode indicar uma insatisfação com as legendas eleitas anteriormente e a busca por alternância no poder. Essas hipóteses apenas podem ser confirmadas com testes específicos, que extrapolam o escopo deste artigo.

Tabela 2

Média da volatilidade eleitoral partidária

\begin{tabular}{|l|c|c|c|c|}
\hline & $\mathbf{2 0 0 0 - 2 0 0 4}$ & $\mathbf{2 0 0 4 - 2 0 0 8}$ & $\mathbf{2 0 0 8 - 2 0 1 2}$ & $\mathbf{2 0 1 2 - 2 0 1 6}$ \\
\hline Pequenos & 39,6 & 38,2 & 37,7 & 41,3 \\
\hline Médios & 38,3 & 37,9 & 37,9 & 43,0 \\
\hline Grandes & 30,9 & 30,7 & 30,6 & 34,4 \\
\hline Geral & 36,0 & 35,4 & 35,2 & 39,4 \\
\hline
\end{tabular}

Fonte: Elaborada pela autora com base nos dados do TSE.

Não há pesquisas que tratem do voto para vereador com a mesma abordagem proposta aqui e, por isso, não é possível afirmar se esse valor aumentou ou diminuiu em relação ao período anterior. Entretanto, é possível comparar em relação a outros cargos legislativos que já foram estudados. Braga (2006) apresenta a média da volatilidade eleitoral partidária para a Câmara dos Deputados e para as Assembleias Legislativas no período de 1990 a 2002. Mesmo se tratando de outro nível de disputa, são cargos com eleições proporcionais, que fazem com que o cálculo do eleitor esteja submetido a regras 
e processos de escolha análogos.

Os valores encontrados para o cargo de vereador são menores porém próximos àqueles encontrados por Braga (2006). Em relação aos portes, apesar de a presente classificação ser um pouco diferente da realizada pela autora ${ }^{11}$, percebe-se a mesma tendência, com valores menores para os municípios considerados grandes, tendência que a autora justifica com base no tempo de atuação das legendas nesses locais. Segundo Braga (2006), lugares nos quais os partidos atuam há mais tempo propiciam maior reconhecimento dessas legendas pelo eleitorado e formações de preferências mais sólidas e estáveis. Nesse mesmo sentido, Mainwaring e Zoco (2007) afirmam que sistemas partidários mais antigos tendem a apresentar menor volatilidade, novamente indicando o fortalecimento dessa relação entre eleitores e partidos, que geraria maior estabilidade ${ }^{12}$.

No Gráfico 1 são apresentadas as médias da volatilidade eleitoral partidária por região e para cada tamanho de município, visando a um maior detalhamento dos dados ${ }^{13}$ :

Gráfico 1

Média da volatilidade eleitoral por região de 2000 a 2016

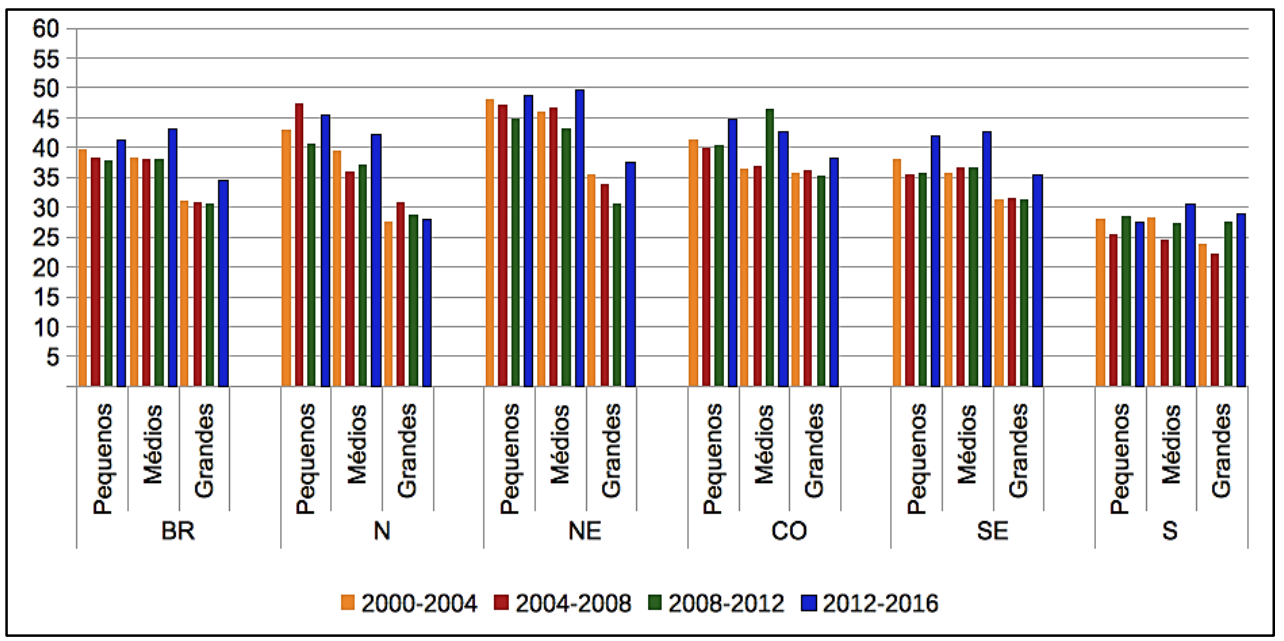

Fonte: Elaborado pela autora a partir de dados do TSE.

A região Sul e, em alguma medida, a Sudeste apresentam a menor volatilidade eleitoral partidária. Esse achado pode ser entendido seguindo o que foi apresentado por Braga (2006), que credita a maior estabilidade dessas regiões à instauração tardia do multipartidarismo. Esse processo facilitaria a formação de preferências eleitorais e,

\footnotetext{
${ }^{11}$ A autora considera como municípios grandes aqueles com, aproximadamente, 200 mil a 600 mil eleitores, e como capitais aqueles com, aproximadamente, 80 mil a 7 milhões de eleitores.

12 Neste artigo serão testadas também hipóteses referentes à maior heterogeneidade de municípios maiores, que geraria maior diversidade de preferências e alternância em escolhas eleitorais, aumentando a volatilidade eleitoral. Os resultados são apresentados na Tabela 3.

${ }^{13}$ A Tabela 4 com os valores da média da volatilidade eleitoral partidária para cada porte municipal em todas as regiões está nos Anexos.
} 
consequentemente, a maior estabilidade do sistema partidário. Novamente, a variável tempo aparece como possível explicação para a formação de relações mais estáveis e duradouras (Braga, 2006; Mainwaring e Zoco, 2007).

Além disso, há níveis de volatilidade eleitoral comparativamente menores nos municípios grandes da região Norte, que também se destacam como únicos nos quais não houve aumento da volatilidade no período 2012-2016. Novamente, explicar o que aconteceu em 2016 requer análises que não se aplicam no presente artigo, mas caberia explorar se as hipóteses sobre oferta partidária e idade do sistema levantadas acima se confirmam ou se esses municípios não foram tão afetados pelo que ocorreu nos últimos anos. De todo modo, esse achado não rejeita totalmente a hipótese da temporalidade sobre a volatilidade eleitoral. Apesar de o pluripartidarismo ter se instaurado mais tardiamente na região Norte (Braga, 2006), provavelmente isso teve início nos municípios maiores e capitais, o que poderia ajudar a justificar esse resultado. Ainda assim, seria uma exceção se comparados com os municípios grandes das demais regiões, o que implica análise e testes mais específicos.

É importante pontuar que outros elementos também podem interferir nesse valor. Municípios podem ter graus distintos de identificação partidária, podem haver bases partidárias consolidadas em locais específicos ou até estratégias partidárias de competição que ajudem a reduzir a volatilidade eleitoral, como a formação de alianças, por exemplo. O presente artigo não explora essas características, mas também não as ignora. Assim, essas questões são apontadas como possíveis agendas de pesquisa futura, que são mais exploradas nas "Considerações finais", e aqui trazemos hipóteses alternativas que já foram testadas previamente e que podem ajudar a explicar tais eventos.

Dando continuidade a esta análise, na Tabela 3 são apresentados os resultados significativos da relação entre as características contextuais selecionadas e a volatilidade eleitoral partidária. Novamente os dados são apresentados para cada porte de municípios e par eleitoral, buscando facilitar a identificação de diferenças entre cada tipo de município e ao longo dos anos, e compará-los ${ }^{14}$ :

14 Os resultados completos estão nos Anexos, na Tabela 4. 
Tabela 3

Variáveis estatisticamente significativas

(volatilidade eleitoral partidária)

\begin{tabular}{|c|c|c|c|c|c|c|c|c|c|c|c|c|}
\hline & \multicolumn{4}{|c|}{ Pequenos } & \multicolumn{4}{|c|}{ Médios } & \multicolumn{4}{|c|}{ Grandes } \\
\hline & $\begin{array}{l}2000 \\
2004\end{array}$ & $\begin{array}{l}2004 \\
2008\end{array}$ & $\begin{array}{l}2008 \\
2012\end{array}$ & $\begin{array}{l}2012 \\
2016\end{array}$ & $\begin{array}{l}2000 \\
2004\end{array}$ & $\begin{array}{l}2004 \\
2008\end{array}$ & $\begin{array}{l}2008 \\
2012\end{array}$ & $\begin{array}{l}2012 \\
2016\end{array}$ & $\begin{array}{l}2000 \\
2004\end{array}$ & $\begin{array}{l}2004 \\
2008\end{array}$ & $\begin{array}{l}2008 \\
2012\end{array}$ & $\begin{array}{l}2012 \\
2016\end{array}$ \\
\hline IDHM & $*$ & $*$ & $*$ & $*$ & $*$ & $*$ & $*$ & $*$ & $*$ & $*$ & $*$ & \\
\hline $\begin{array}{l}\text { Número de } \\
\text { eleitores }\end{array}$ & & & $*$ & $*$ & & & - & & & & & \\
\hline $\begin{array}{l}\text { População } \\
\text { rural }\end{array}$ & $*$ & $*$ & $*$ & $*$ & & & $*$ & & $*$ & & $*$ & $*$ \\
\hline NEP & & $*$ & $*$ & $*$ & $*$ & $*$ & & $*$ & $*$ & & & $*$ \\
\hline $\begin{array}{l}\text { Magnitude do } \\
\text { distrito }\end{array}$ & & & & & & & & & & & & \\
\hline
\end{tabular}

Fonte: Elaborada pela autora a partir dos resultados dos testes realizados.

* = variáveis significativas que confirmaram as hipóteses.

- = variáveis significativas que negaram as hipóteses.

De um modo geral, nota-se que o contexto ajuda a explicar a volatilidade eleitoral partidária nos municípios brasileiros. Mas é preciso ressaltar que não é possível identificar nenhum comportamento constante de nenhuma variável ao longo do tempo. Esses achados indicam que algumas características impactam o voto, mas apenas sob certas condições. Primeiro, são apresentados os efeitos das variáveis independentes selecionadas. Em seguida, apontamentos mais detalhados sobre a diferença desses efeitos em cada porte de município e ao longo dos anos em que foram pesquisados.

A variável com maior impacto sobre a volatilidade eleitoral partidária é o IDHM. Além de explicar a mudança nas preferências eleitorais em quase todos os períodos e para praticamente todos os tamanhos de municípios, ele apresenta os coeficientes padronizados mais altos, indicando seu maior grau de influência sobre a variável dependente em comparação com as demais. Esse achado corrobora o que foi apresentado por Mainwaring e Torcal (2005) e Mainwaring e Zoco (2007), e indica que em municípios mais desenvolvidos há relações mais positivas, sólidas e duradouras entre eleitores e partidos políticos.

O número de eleitores apresenta comportamento que difere do que era esperado, com exceção do relacionado a municípios pequenos, para os quais se confirmam as hipóteses, mas em pequena medida. Já a porcentagem de população rural se mostrou significativa e no mesmo sentido da hipótese em todos os pares eleitorais nos municípios pequenos. Ou seja, isso sugere que nesses locais o modo de vida da população de fato é 
mais homogêneo e que isso gera preferências mais estáveis, indo ao encontro da ideia das clivagens de Lipset e Rokkan (1967). Não é possível traçar conclusões robustas sobre essa variável, pois seu comportamento foi irregular nos municípios médios, com efeito apenas no par 2008-2012, e oscilou nos municípios grandes. Mas em todas as ocasiões o sentido da relação foi negativo, o que pode indicar a existência de clivagens específicas em cada um desses momentos.

Assim, de um modo geral, não foi possível comprovar totalmente a hipótese da menor heterogeneidade de municípios pequenos, nem a existência de clivagens rurais, no sentido do que foi apresentado por Lipset e Rokkan (1967). Ambas as variáveis apresentaram relações irregulares e, em algumas ocasiões, fracas, o que nos remete novamente à necessidade de pensar sobre alternativas explicativas e de explorar outras variáveis explicativas.

Em relação às variáveis institucionais, apenas o número efetivo de partidos se mostra significativo, principalmente nos municípios pequenos e médios. A magnitude do distrito não apresenta nenhum poder explicativo, indicando que um maior número de vagas não é condição suficiente para produzir contextos políticos mais voláteis. O baixo efeito do NEP nos municípios grandes e a não importância do número de vagas ao longo de todo o período e para todos os portes de cidades sugerem que o efeito dessas características institucionais pode depender também do grau de estabilidade da oferta partidária na competição eleitoral. Ainda assim, os resultados demonstram que a volatilidade eleitoral nos municípios brasileiros também sofre influência da fragmentação do sistema, do mesmo modo que ocorre nos estados brasileiros e em outros países da América Latina (Mainwaring, 2001; Mainwaring e Zoco, 2007; Peres, Ricci e Rennó, 2011).

Sabendo o efeito de cada variável, vale explorar suas diferenças para cada porte de município. Percebe-se que os municípios pequenos são aqueles que sofrem maior impacto das variáveis contextuais, principalmente sociodemográficas. Em seguida, vêm os municípios médios e, por fim, os grandes. É possível verificar essa tendência pelo grau de significância mais elevado que as variáveis apresentam, mas também pelo maior número de variáveis que impactam sobre a volatilidade eleitoral partidária e pelo maior valor de seus coeficientes. À medida que os municípios crescem, essas características perdem seu poder de influência como também diminui a intensidade dessa relação, quando existe.

Nos municípios grandes nota-se um menor impacto das variáveis institucionais, que estão relacionadas principalmente com a oferta de partidos. Por um lado, isso pode ser compreendido recuperando a questão da temporalidade do sistema partidário e de seu impacto sobre a construção de lealdades partidárias (Braga, 2006; Mainwaring e Zoco, 2007), uma vez que em municípios grandes espera-se encontrar uma presença partidária mais antiga e, por isso, consolidada, fazendo com que o aumento no número de competidores impacte menos sobre a decisão do eleitor por ser esta mais estável. Mas isso pode ocorrer também pela maior complexidade estrutural que esses locais apresentam, em que atuam outros elementos capazes de afetar o comportamento eleitoral e partidário, 
como a existência de redutos e demandas específicas.

Cabe pontuar que o tamanho do município tem impacto sobre algumas das variáveis selecionadas e como elas afetam a volatilidade eleitoral. Por exemplo, a porcentagem de população rural ou o número de vagas, que é calculado levando-se em consideração a representatividade da população. Sendo assim, já era esperado encontrar essa diferença entre os grupos de municípios, com algumas variáveis tendo efeito regular apenas em contextos específicos, como ocorreu com a porcentagem da população rural nos municípios pequenos, e outras apresentando impacto em praticamente todos os casos, como o IDHM. O importante a ser ressaltado aqui é que os resultados encontrados reforçam a necessidade de tratar esses locais de modo distinto.

Agora tratando especificamente do período temporal analisado, nota-se que também há diferenças nos efeitos. Nos municípios médios e grandes o impacto das variáveis contextuais oscilou consideravelmente ao longo do tempo, enquanto nos municípios menores esse efeito é mais contínuo e significativo. Esse achado reforça a necessidade de considerar o contexto e a conjuntura política particular a cada período eleitoral, pois também podem afetar o comportamento partidário e eleitoral.

Outro elemento que vale destacar é o que acontece nas eleições de 2012-2016 nos municípios grandes, que é a única ocasião na qual o IDHM não apresenta efeito. Já foi indicado que a situação de instabilidade do cenário político brasileiro gerou um aumento da volatilidade eleitoral e pode ter inserido novos elementos no cálculo eleitoral. Com isso, abre-se uma lacuna de pesquisa e a necessidade de buscar características distintas que expliquem a dinâmica eleitoral de 2016, principalmente políticas e conjunturais.

De modo resumido, as variáveis contextuais que impactam a volatilidade eleitoral partidária são, principalmente, o IDHM, a porcentagem de população rural e o NEP. Essas três características foram significativas em quase todos os portes de municípios e pares eleitorais analisados. Nos municípios pequenos, há também algum impacto do número de eleitores de 2008 a 2016, mas seu efeito é pequeno. Para os municípios médios e grandes, os efeitos das variáveis são mais discretos e irregulares. O mesmo pode ser dito em relação ao efeito das variáveis no decorrer dos anos, não apresentando padrão.

Apesar das diferenças encontradas entre os grupos, é possível afirmar que as variáveis contextuais (sociodemográficas e institucionais) ajudam a explicar a volatilidade eleitoral partidária e, assim, o comportamento eleitoral nos municípios. A mudança do voto para vereador no Brasil é, portanto, influenciada pelas condições de vida local, pela condição social dos eleitores para definir sua preferência partidária e se manter estáveis a ela, pelo processo de socialização pessoal e político e pela oferta partidária de cada eleição, sendo que este último fator influencia em menor escala. Além disso, nota-se que há diferença entre os grupos de municípios, com variáveis importando em alguns deles e em outros não, o que implica a necessidade de maiores explorações a fim de explicar o que causa essas diferenças nos efeitos das variáveis. 


\section{Considerações finais}

O presente artigo tem como objetivo compreender por que alguns municípios possuem eleitores com comportamento mais volátil do que outros. Essa análise é realizada por dois caminhos: o primeiro consiste em um exercício exploratório e descritivo, que apresenta a média da volatilidade eleitoral partidária para cada grupo de municípios e região; o segundo, de caráter mais analítico, tem como proposta identificar quais características do contexto local são capazes de explicar essa flutuação nas votações partidárias.

Constata-se uma tendência de continuidade nos valores do índice de volatilidade eleitoral no sistema partidário subnacional, que segue o que foi apresentado para outros pleitos, como o presidencial, os governos estaduais, o Senado, a Câmara dos Deputados e as Assembleias Legislativas (Braga, Ribeiro e Amaral, 2012; Peres, Ricci e Rennó, 2011; Bohn e Paiva, 2009; Braga, 2006). A exceção está no último par eleitoral, no qual nota-se um leve aumento desses valores, o que talvez possa ser explicado pelos últimos acontecimentos políticos pelos quais o país passou.

Os resultados dessas análises apontam uma relação importante. Apesar de os municípios pequenos apresentarem índices um pouco mais elevados se comparados com os outros dois grupos, nesses locais a volatilidade eleitoral pode ser mais bem compreendida por meio de características contextuais. Nos municípios grandes, as escolhas eleitorais parecem ser mais contínuas no tempo e não possuem tanta relação com as características contextuais. Essa evidência pode estar relacionada à ideia de uma presença partidária mais numerosa e antiga, e de um sistema partidário estabelecido há mais tempo, o que facilitaria a consolidação das relações entre o eleitor e o partido político de sua preferência apontada por Braga (2006) e Mainwaring e Zoco (2007).

Dentro desses achados, o IDHM e o número efetivo de partidos são os indicadores que apresentam maior capacidade explicativa para a volatilidade eleitoral, e, em alguma medida, a porcentagem de população rural, ainda que o NEP e a porcentagem da população rural atuem de forma irregular. Isso remete aos achados encontrados em análises comparativas entre países da América Latina e no Brasil (Roberts e Wibbels, 1999; Mainwaring e Torcal, 2005; Mainwaring e Zoco, 2007; Bohn e Paiva, 2009; Peres, Ricci e Rennó, 2011). Assim, é possível confirmar que, também para os municípios brasileiros, a oferta partidária, a composição territorial e o grau de desenvolvimento local são importantes para explicar a variação na escolha eleitoral.

Essa evidência confirma a importância de analisar de forma mais profunda a volatilidade eleitoral, e de não a aceitar, diretamente, como um indicativo do grau de estabilidade do sistema partidário. Um sistema com alto índice de volatilidade eleitoral não demonstra, necessariamente, a ausência de consolidação. Os motivos para as flutuações 
podem estar ligados a características pontuais de cada local e não a algum problema intrínseco ao sistema político ${ }^{15}$.

Esses achados abrem ainda possibilidade de novas agendas de pesquisa. Por que algumas variáveis se mostram tão significativas em alguns grupos de municípios ou períodos específicos e em outros não? Que outras variáveis podem estar afetando e interferindo nessa relação?

Uma possível exploração seria incluir a oferta partidária de cada local. Isso permitiria verificar o quanto ela varia ao longo do tempo e ponderar em que medida os eleitores mudam de partido por não terem as mesmas opções disponíveis em cada eleição. Além disso, permitiria verificar o efeito da migração partidária, observando se eleitores escolhem partidos diferentes em eleições consecutivas acompanhando a movimentação de candidatos específicos.

O esforço deste artigo foi o de lançar um primeiro olhar para uma característica muito importante do sistema partidário, mas sob uma perspectiva alternativa e em locais ainda pouco explorados. Buscou-se entender o comportamento político no nível local e identificar o papel do contexto dentro da dinâmica do sistema partidário. Demonstrou-se que essa relação existe, mas ainda há lacunas que precisam ser preenchidas.

\section{Referências bibliográficas}

BOHN, S. R.; PAIVA, D. "A volatilidade eleitoral nos Estados: sistema partidário e democracia no Brasil". Revista de Sociologia e Política, Curitiba, vol. 17, no 33, p. 187-208, 2009.

BORNSCHIER, S. "Cleavage politics in old and new democracies". Living Reviews in Democracy, vol. 1, $\mathrm{n}^{\circ} 1$, p. 1-13, 2009.

BRAGA, M. S. S. O processo partidário-eleitoral brasileiro: padrões de competição política (19822002). São Paulo: Associação Editorial Humanitas/Fapesp, 2006.

Braga, M. S. S.; Ribeiro, P. F.; AmARAL, O. E. "El sistema de partidos en Brasil: estabilidad e institucionalización". VI Congreso Latinoamericano de Ciencia Político (Alacip). Quito, 12 a 14 de junho de 2012.

DALTON, R. J. Political cleavages, issues, and electoral change. In: LedUC, L.; NIEMI, R. G.; NORRIS, P. (eds.). Comparing democracies: elections and voting in global perspective. Thousand Oaks, CA: Sage Publications, p. 319-342, 1996.

DALTON, R. J.; ANDERSON, C. (eds.). Citizens, context and choice: how context shapes citizens' electoral choices. Oxford: Oxford University Press, 2011.

\footnotetext{
${ }^{15}$ Alguns trabalhos exploram mais detidamente possíveis problemas no cálculo da volatilidade eleitoral e
} possibilidades de interpretação espúrias. Para mais detalhes, ver Mair (1997), Peres (2013) e Zucco (2015). 
Figueiredo, M. A. Decisão do voto: democracia e racionalidade. $2^{a}$ ed. Belo Horizonte: Editora UFMG, 2008.

LAAKSO, M.; TAAGEPERA, R. "'Effective' number of parties: a measure with application to West Europe". Comparative Political Studies, vol. 12, no 1, p. 3-27, 1979.

LIPSET, S. M. O homem político. Rio de Janeiro: Zahar Editores, 1967.

LIPSET, S. M.; ROKKAN, S. (eds.). Party systems and voter alignments: cross-national perspectives. New York: Free Press, 1967.

MAINWARING, S. Sistemas partidários em novas democracias: o caso do Brasil. Porto Alegre: Mercado Aberto; Rio de Janeiro: FGV, 2001.

Mainwaring, S.; SCully, T. R. Party systems in Latin America. In: Mainwaring, S.; Scully, T. (eds.). Building democratic institutions: party systems in Latin America. Stanford: Stanford University Press, 1995.

MAINWARING, S.; TORCAL, M. "Teoria e institucionalização dos sistemas partidários após a terceira onda de democratização". Opinião Pública, vol. 11, no 2, p. 249-286, 2005.

MAINWARING, S.; Zoco, E. "Political sequences and the stabilization of interparty competition: electoral volatility in old and new democracies". Party Politics, vol. 13, no 2, p. 155-178, 2007.

MAIR, P. Party system changes: approaches and interpretations. United States: Oxford University Press, 1997.

The freezing hypothesis: an evaluation. In: Karvonen, L. ; KUHNLE, S. (eds.). Party systems and voter alignments revisited. London/New York: Routledge, 2001.

PEDERSEN, M. N. "The dynamics of European party systems: changing patterns of electoral volatility". European Journal of Political Research, vol. 7, no 1, p. 1-26, 1979.

Patterns of electoral volatility in European party systems: explorations in explanation. In: DAALDER, H. ; MAIR, P. (eds.). Western European party systems: continuity and change. Londres, 1983.

PERES, P. "Institucionalização do sistema partidário ou evolução da competição? Uma proposta de interpretação econômica da volatilidade eleitoral". Opinião Pública, vol. 19, nº 1, p. 21-48, 2013.

Peres, P.; RICCI, P.; REnNó, L. R. "A variação da volatilidade eleitoral no Brasil: um teste das explicações políticas, econômicas e sociais". Latin American Research Review, vol. 46, no 3, p. 46$68,2011$.

Roberts, K. M.; Wibbels, E. "Party systems and electoral volatility in Latin America: a test of economic, institutional, and structural explanations". American Political Science Review, vol. 93, no 3, p. 575-590, 1999.

TAAgePerA, R.; ShugART, M. S. Seats and votes: the effects and determinants of electoral systems. New Haven: Yale University Press, 1989.

Zucco, C. Estabilidad sin raíces: la institucionalización del sistema de partidos brasileños. In: TORCAL, M. (org.). Los problemas de la institucionalización de los sistemas de partidos en América Latina. Barcelona: Cidob, 2015. 


\section{Abstract}

The electoral volatility of local legislators at the municipal level in Brazil (2000-2016)

The central aim of this research is to demonstrate that the local (sociodemographic and institutional) context helps explain changes in voters' vote choice in support of different political parties. This research analyzes the electoral volatility index for local legislators in four municipal elections-2000, 2004, 2008, 2012 and 2016-with a sample of all Brazilian cities. This work contributes to the literature about both electoral behavior and party systems. The results show that the contextual variables have a more intense effect in small municipalities and at the beginning of the analyzed period.

Keywords: electoral volatility; municipal elections; electoral behavior; party systems; local legislator

\section{Resumen}

La volatilidad electoral en los municipios brasileños para el cargo de edil (2000-2016)

El objetivo de este artículo es demostrar que el contexto local (sociodemográfico e institucional) ayuda a explicar la alternancia en la decisión del elector entre los diversos partidos políticos. Para eso, se analiza el índice de volatilidad electoral partidaria para el cargo de edil en cinco elecciones consecutivas - 2000, 2004, 2008, 2012 y 2016 - teniendo como base una muestra representativa de todos los municipios brasileños y tratando ese índice como variable dependiente. Así, el artículo contribuye para la literatura sobre sistema partidario y sobre comportamiento electoral. Los resultados encontrados indican un efecto más expresivo de las variables contextuales entre los municipios de menor población y al inicio del período analizado.

Palabras clave: volatilidad electoral; elecciones municipales; comportamiento electoral; sistema partidario; edil

\section{Résumé}

La volatilité électorale dans les communes brésiliennes pour le poste de conseiller municipal (20002016)

L'objectif de cet article est de démontrer que le contexte local (sociodémographique et institutionnel) aide à expliquer l'alternance dans la décision de l'électeur entre les différents partis politiques. Pour cela, on analyse le taux de volatilité électorale partisane pour le poste de conseiller municipal au cours de cinq élections consécutives - 2000, 2004, 2008, 2012 et 2016 - en se fondant sur un échantillon représentatif de toutes les communes brésiliennes et en abordant ce taux comme une variable dépendante. Ainsi, I'article apporte une contribution à la littérature sur les systèmes partisans et sur le comportement électoral. Les résultats obtenus indiquent un effet plus expressif des variables contextuelles entre les petites communes et au début de la période analysée.

Mots-clés: volatilité électorale; élections municipales; comportement électoral; système partisan; conseiller municipal Versão final aprovada em 29 de outubro de 2018.

Opinião Pública adota a licença Creative Commons CC-BY.

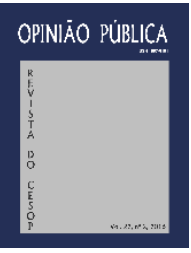

